
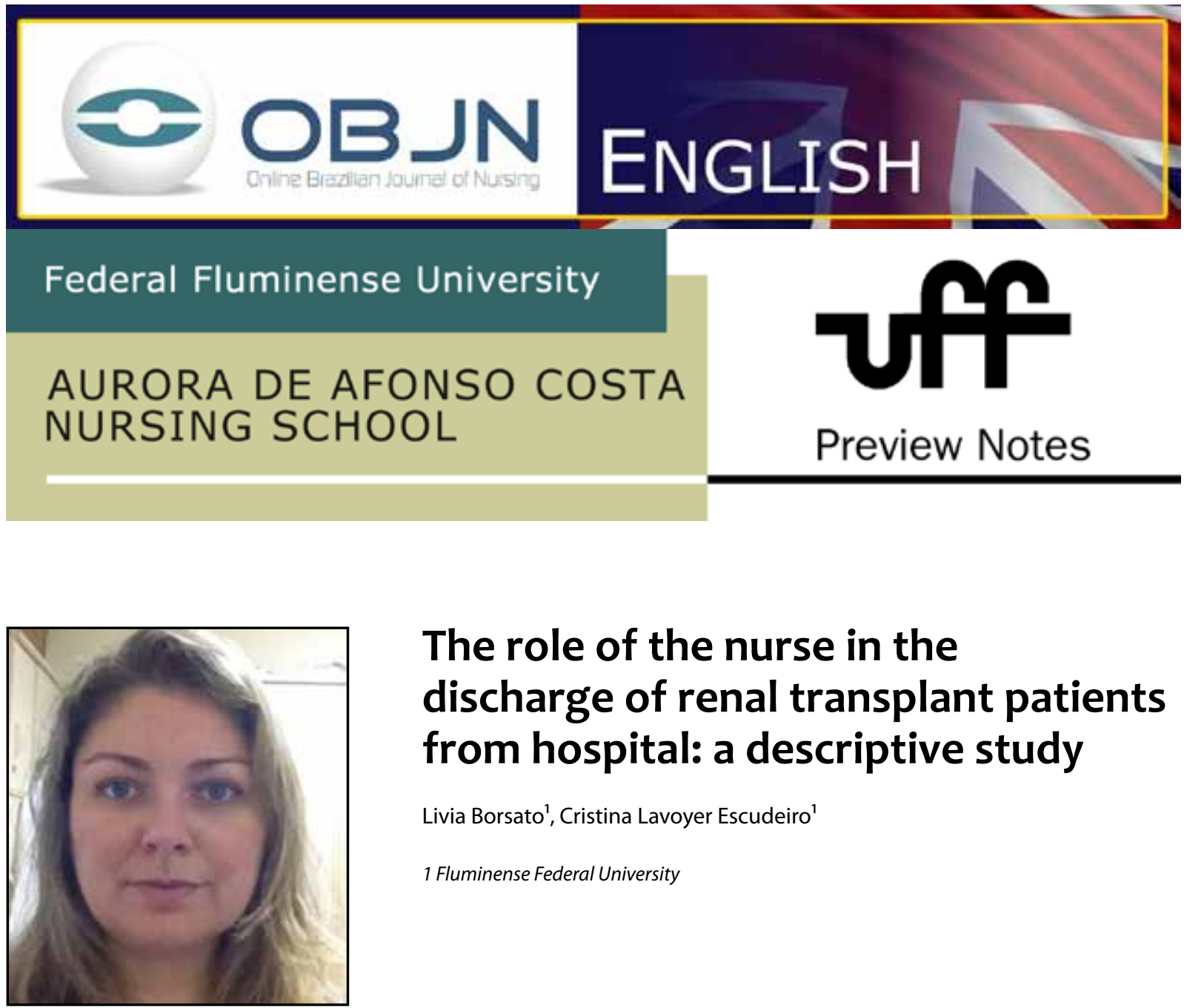

\title{
The role of the nurse in the discharge of renal transplant patients from hospital: a descriptive study
}

\author{
Livia Borsato', Cristina Lavoyer Escudeiro \\ 1 Fluminense Federal University
}

\section{ABSTRACT}

This is a dissertation project as part of the Professional Master's in Healthcare Nursing, Fluminense Federal University. Aims: To develop a protocol for nursing guidelines for the discharge of renal transplant patients from hospital; to identify the practices performed by nurses at the moment of hospital discharge for renal transplant patients, and describe the knowledge that guides their activities at that time. Method: This is a descriptive study in which a qualitative approach will be used. The scenario will be the Dialysis and Transplant Center (DTC) of a public hospital located in the city of Niterói, Rio de Janeiro; the six nurses employed in the Center will act as subjects. Data will be collected through semi-structured interviews in the months from July to August 2014 and will be submitted to content analysis.

Descriptors: Kidney Transplantation; Nursing Care; Self Care. 


\section{PROBLEM SITUATION AND ITS SIGNIFICANCE}

Kidney transplantation is the ideal treatment for patients with chronic renal failure, and it is mandatory for those who do not present technical conditions for the installation/ maintenance of central venous access and/ or peritoneal access. With the introduction of transplantation as a therapeutic option, the number of patients who are able to receive treatment for previously untreatable diseases has increased significantly in Brazil( ${ }^{(1)}$. The National Transplant System (NTS) is the largest public transplant program in the world. The Ministry of Health provides about one billion dollars annually for the NTS(2).

Over $95 \%$ of transplants are performed as part of the Unified Health System (UHS) and the monitoring of all these patients is in general linked to the transplant teams. All transplant policy is in line with laws No. 8,080/1990 and No. $8,142 / 1990$, which govern the operation of the UHS ${ }^{(2)}$. Despite difficulties, Brazil has progressively improved its performance. A total of 3,463 (18.8 per million people - pmp) kidney transplants were conducted in 2007, while by 2012 that number had risen to 5,385 (28.2 pmp). This increase is primarily due to the growing number of effective deceased donors, which was $18.8 \mathrm{pmp}$ in 2007 and rose to 28.2 pmp in $2012^{(3)}$.

Due to the specificity of kidney transplantation, the guidelines for these patients are also specific, since there are many possible complications in the postoperative period. Thus, there is a clear need for a multidisciplinary team that knows how to identify such complications in order to take action rapidly. Since nurses are the professionals who care for the patient throughout the days following the operation, they can recognize the signs and symptoms of surgical, cardiac, allograft rejection, and infection complications. For a successful transplantation, the participation of nurses at all stages of the process is essential, from the care provided to the donor of multiple organs and tissues, to the care provided to patients in the post-transplantation period. These patients require experienced professionals and specialized care $^{(3)}$.

Kidney transplantation has a high cost that increases with every rehospitalization. Therefore it is necessary to minimize the risk in terms of the return of the transplanted patient to the unit, thus justifying the importance of nursing guidelines. With this study, we hope to contribute to the standardization of care by creating a protocol.

\section{GUIDING QUESTIONS}

What are the practices performed by nurses during the hospital discharge of renal-transplant patients?

What knowledge guides the nursing staff at that moment?

How is it possible to develop a protocol of nursing guidelines for hospital discharge aimed at the support of renal-transplant patients?

\section{AIMS}

General aim: to develop a protocol of nursing guidelines for hospital discharge aimed at supporting renal transplant patients.

Specific aims:

- To identify the practices of nurses at the time of hospital discharge aimed at supporting renal transplant patients;

- To describe the knowledge that guides nursing practice at the time of the hospital discharge of these patients. 


\section{METHOD}

This is a descriptive study in which a qualitative approach will be used. The scenario will be the Dialysis and Transplant Center (DTC) of a public hospital located in the city of Niterói, Rio de Janeiro. Data collection will take place in two stages. First a literature review in terms of the nursing guidelines recommended for use with renal transplant patients will be performed. In the second stage, semi-structured interviews following a previously developed question script will be carried out. The study subjects are nurses of the Center involved, totaling six nurses. Data collection will be done through interviews in the period from July to August 2014, and they will be recorded and transcribed in full, maintaining the confidentiality of the participants. As an inclusion criterion, the individual should be a nurse on the permanent staff of the DTC in the hospital where the research will be performed. The exclusion criterion is: professionals who are on vacation or leave during the period of data collection. The analysis and interpretation of the data will take place in three stages: (I) analysis of the literature review; (II) evaluation of the interviews performed with nurses through use of Bardin's content analysis; (III) data crossing of the literature findings and the interview analysis for the construction of the protocol. The study was approved under Opinion No. 655193 by the Research Ethics Committee of the hospital that will be the locus of this study, thus ensuring that the ethical and legal principles related to human research are respected.

\section{REFERENCES}

1. Virgínio $B C A E$, Escudeiro $C L$, Christovam $B P$, Silvino ZR, Guimarães TCF, Oroski G. Death and organ donation from the point of view of nurses: a descriptive study. Online Braz J Nurs [internet]. 2014 Mar [cited 2014 Jul 02]; 13(1):92-101. Available from: http://www.objnursing.uff.br/index. php/nursing/article/view/4164

2. Medina-Pestana JO, Galante NZ, Tedesco-Silva Jr H, Harada KM, Garcia VD, Abbud-Filho M, et al. Kidney transplantation in Brazil and its geographic disparity. J Bras Nefrol [internet]. 2011 Oct/Dec [cited 2014 Jun 15]; 33(4):472-84. Available from: http://www.scielo.br/pdf/jbn/v33n4/ en_14.pdf.

3. Pestana JOM, Freitas TVS, Silva Junior HT. Transplante renal: manual prático, uso diário ambulatorial e hospitalar. São Paulo: Livraria Balieiro; 2014.

All authors participated in the phases of this publication in one or more of the following steps, in According to the recommendations of the International Committee of Medical Journal Editors (ICMJE, 2013): (a) substantial involvement in the planning or preparation of the manuscript or in the collection, analysis or interpretation of data; (b) preparation of the manuscript or conducting critical revision of intellectual content; (c) approval of the versión submitted of this manuscript. All authors declare for the appropriate purposes that the responsibilities related to all aspects of the manuscript submitted to OBJN are yours. They ensure that issues related to the accuracy or integrity of any part of the article were properly investigated and resolved. Therefore, they exempt the OBJN of any participation whatsoever in any imbroglios concerning the content under consideration. All authors declare that they have no conflict of interest of financial or personal nature concerning this manuscript which may influence the writing and/or interpretation of the findings. This statement has been digitally signed by all authors as recommended by the ICMJE, whose model is available in http://www. objnursing.uff.br/normas/DUDE_eng_13-06-2013.pdf

Received: $07 / 22 / 2014$

Revised: 08/22/2014

Approved: 08/22/2014 